\section{Imagery and the recall of adjectives and nouns from meaningful prose}

\author{
P. E. MORRIS* and R. L. KEID \\ University of Exeter, Exeter, England
}

Two experiments investigated the role of the imagery-evoking (I) value of words in the recall of the contents of a passage of connected prose. In Experiment 1, Ss studied a passage into whirh either high- or low-I adjectives had been inserted. They were first asked to recall the nouns and then, given the nouns, to recall the adjectives. Significantly more high-I than low-I adjectives were recalled, but the nouns qualified by high-I adjectives were no more frequently recalled than those qualified by low-I adjectives. In Experiment 2, I ratings of the nouns in the passage were obtained both in their context in the passage and independently as a list. Both sets of ratings correlated significantly with the recall of the nouns in Experiment 1, the correlation being significantly higher for the rating in context.

The image-evoking (I) value of words has been shown to affect free recall, paired-associate, and serial learning (Paivio, 1969). Morris \& Reid (1971) demonstrated that the free recall of simple grammatical units consisting of adjective-noun pairs is affected by the I of both the adjective and the noun. The experiments described below extend the investigation to study recall from a passage of connected prose. Reading a prose passage with the intention of answering questions afterwards comes closer to everyday life than earlier research, making it unlikely that any effects of I would be the result of Ss' adopting strategies of learning that are peculiar to the psychology laboratory.

Kirchner (1969) examined the effects of inserting into a short narrative passage adjectives rated high or low in vividness (V). Values of $\mathrm{V}$ were obtained from ratings on a 7-point vivid-colorless scale. The Ss who heard the version with the more vivid adjectives wrote more in an immediate test of free recall and recalled more nouns but did not recall significantly more of the adjectives themselves. The result was unexpected, and it suggested to Kirchner that the vividness of an adjective might have an energizing or alerting function acting differentially upon the noun qualified by the adjective.

The experiment that follows was designed independently of Kirchner's experiment but on similar lines to investigate the effects of varying the I values of adjectives. On the basis of the experiment by Morris and Reid, it was predicted that nouns qualified by high-I adjectives would be recalled more frequently than nouns qualified by low-I adjectives. Since Yuille, Paivio, \& Lambert (1969) found better

\footnotetext{
*Supported by S.S.R.C. grant.
}

paired-associate learning of adjective-noun pairs with high-I adjectives, it was also predicted that Ss given the nouns would recall more of thehigh-I than of the low-I adjectives. Only the second of these predictions was found to be true. Noun recall was qualifying adjectives.

In order to find out whether the recall of nouns had been affected by the I values of the nouns themselves, a second experiment was carried out in which the nouns were rated when presented either in context in the passage or independently in the form of a list. Both sets of I ratings were then correlated with frequency of noun recall.

\section{EXPERIMENT 1} Adjective I

Ratings of I for 97 common adjectives, obtained following the procedure of Paivio, Yuille, \& Madigan (1968), were available from the earlier experiment by Morris \& Reid (1971). Passage

The beginning of E. M. Forster's short story The Road from Colonus was adapted by deleting all adjectives, except two that were necessary for the sense of the passage. Version $L$ was prepared by adding 18 low-I adjectives (mean $=3.12$, range $=1.75$ to 4.02 ) and Version $\mathrm{H}$ by adding 18 high- 1 adjectives (mean $=5.46$, range $=4.80$ to 6.00 ). The passage with both sets of adjectives is given below.

"For no (little/happy) reason Mr. Lucas had hurried ahead of his (slow/drunken) party. He was reaching the age at which independence becomes valuable because it is so soon to be lost. Tired of (continuous/tender) attention and (kind/calm) consideration he liked breaking away from the younger members to ride by himself and dismount unassisted. Perhaps he also relished that (simple/glowing) pleasure of being kept waiting for lunch and of telling the others on their not affected by the I values of arrival that it was of no consequence. So, with (great/burning) impatience he battered his animal's sides with his (big/polished) heels and made the muleteer bang it with his (lengthy/green) stick and jolted down the hillside through (single/brown) shrubs till he heard the sound of (invisible/running) water and came in sight of the group of (young/tall) trees where they were to have their (next/hot) meal. In the midst of the trees was an inn, a (complex/yellow) building with $a(n)$ (essential/red) balcony on which sat a(n) (fabulous/old) woman spinning while a (docile/white) pig eating orange peel stood beside her. On the earth below squatted two (naughty/noisy) children playing a game with their fingers while their (cautious/yawning) mother messed with some rice inside."

Procedure

At the beginning of a first-year psychology practical class, the two versions of the passage were distributed to 56 students, half receiving Version $L$ and half receiving Version $\mathrm{H}$. They were told to read the passage carefully and to be ready to answer questions about it. At the end of a 2-min period, they were asked to turn the passage face down and then to write as many nouns as they could remember on a response sheet. After $3 \mathrm{~min}$, these sheets were collected and a form was distributed giving the 18 nouns which had followed the adjectives in the passage. The Ss were given $3 \mathrm{~min}$ to write the corresponding adjectives beside each noun. One $S$ who received Version $H$ was eliminated for failing to follow instructions.

\section{Results}

Adjective recall. The mean number of adjectives correctly recalled was 4.64 for Version $L$ and 7.96 for Version $H$. The difference, in favor of the version with high-I adjectives, was significant by a Mann-Whitney U test $(\mathrm{U}=147.5, \quad \mathrm{z}=3.87, \quad \mathrm{p}<.001)$ (Siegel, 1956).

Noun recall. The mean numbers of nouns recalled by $S$ s receiving Versions $L$ and $H$ were 12.86 and 12.63 , respectively. Considering only the nouns which had been preceded by an inserted adjective, the mean recall of nouns was 6.93 for Version $L$ and 7.00 for Version $H$. These differences were not significant by a Mann-Whitney $\mathrm{U}$ test.

Order of recall. Scoring each S's recall by counting +1 for each noun that came later in the passage than the previous noun recalled and -1 for each noun that came earlier, scores were positive for $35 \mathrm{Ss}$, zero for 11 , and negative for 9 . A binomial test (Siegel, 1956) gave $z=3.77, p<.001$, showing that the narrative order tended to be followed in free recall. 


\section{EXPERIMENT 2}

Since the recall of nouns in Experiment 1 was independent of adjective $I$, the noun-recall data of the two groups, $L$ and $H$, could be combined in order to investigate the degree to which the I values of nouns influenced their recall.

\section{Method}

Booklets were prepared in which the nouns from the original passage were printed with 7-point low-imagery/high-imagery scales beside them (the compound "orange peel" was left out because of its doubtful grammatical status). The instructions used by Paivio et al (1968) for I ratings of nouns were printed on the first page of the booklets and were read by Ss before they began their rating. One group of 39 psychology undergraduates rated the nouns without seeing the original passage. A second group of $25 \mathrm{Ss}$ read the passage first, 13 receiving Version $L$ and 12 Version $H$. They were then asked to rate the nouns "in their context in the passage."

\section{Results}

The frequency of recall of each of the 34 nouns was obtained from the data of Experiment 1. From the two sets of I ratings (without context and with context), mean ratings were obtained for each noun. For nouns rated without context, mean I was 4.89, range 1.54-6.38, and for nouns with context, mean I was 4.87 , range 1.64-6.44. Product-moment correlations between the three variables were then calculated.

The two I ratings correlated +0.88 ( $\mathrm{df}=32, \quad \mathrm{p}<.005$ ). The rating without context correlated +0.40 with recall ( $\mathrm{df}=32, \mathrm{p}<.025)$, while the rating with context correlated +0.54 with recall (df $=32, p<.005)$. The correlation for ratings with context is significantly higher than that for ratings without context, indicating that the ratings in context were more closely related to recall $(t=2.006$, $\mathrm{df}=31, \mathrm{p}<.05)($ Edwards, 1963). DISCUSSION

In Experiment 1, as predicted, there was more frequent recall of high-I than of low-I adjectives, but the expected facilitation of the recall of nouns by high-I adjectives did not occur. Indeed, the recall of the nouns by the $L$ and $H$ groups could hardly have been more alike. In Kirchner's experiment, the effect of $V$ was to increase noun recall without increasing adjective recall. The reason for the difference in the results may lie in one of the differences between the two studies. The passage from Forster's short story used here was $70 \%$ longer than the one used by Kirchner and very likely of higher literary merit. Also, different methods were used for presentation and for assessing recall. The Ss in Kirchner's experiment were set for literal recall, while in the present experiment, they were set for comprehension. There is the additional possibility that the differences in results may be due to differences between $I$ and $V$. Kirchner attributed energizing, alerting, and arousing effects to vivid adjectives. Although some correlation between I and $V$ would be expected, these motivational effects, which in Kirchner's terms produced "modifier impact," may be less characteristic of I than of $V$.

In Experiment 2, it was found that the I values of individual nouns were correlated with the frequencies with which the nouns were recalled. It is encouraging to find that the I variable can enable predictions to be made when the material to be recalled is very different from the traditional paired associates or lists of items.

Some reasons for the improvement in the correlation of I and recall when nouns are rated in their context are illustrated by the following examples. The word "party" in the narrative refers to a group of people traveling together, not the more obvious and easily imaged kind of party. Given the context which specifies this use of the word, its I value drops from 6.38 to 5.32 ; the opposite effect occurs with "muleteer." Several Ss who performed the ratings without context remarked that the word was unfamiliar to them, a fact reflected in its I rating of 2.33; however, given the context, the ratings rose to 4.42 .

The failure of the I values of the inserted adjectives to influence the recall of the nouns may be accounted for by supposing that, in connected prose, the meaning of each individual word is affected by a large number of other words. Accordingly, in connected prose, the influence of an adjective is one among many influences. If, as in this case, the prose already makes sense without the addition of adjectives, then their effect on other words may well be small, even if they are in themselves memorable.

\section{REFERENCES}

EDWARDS, A. L. Experimental design in psychological research. New York: Holt, 1963.

KIRCHNER, E. P. Vividness of adjectives and the recall of meaningful verbal material. Psychonomic Science, 1969, 15, 71-72.

MORRIS, P. E., \& REID, R. L. Imagery and compatibility of pairing in the free recall of adjective-noun pairs. Quarterly Journal of Experimental Psychology, 1971, 23, 393-398.

PAIVIO, A. Mental imagery in associative learning and memory. Psychological Review, 1969, 76, 241-263.

PAIVIO, A., YUILLE J, C. \& MADIGAN, $S$ Concreteness, imagery and meaningfulness values for 925 nouns. Journal of Experimental Psychology, $1968,76,1-25$.

SIEGEL, S. Nonparametric statistics for the behavioral sciences. New York: MeGraw-Hill, 1956.

YUILLE, J. C., PAIVIO, A., \& LAMBERT, $W$. E. Noun and adjective imagery and order in paired-associated learning by French and English subjects. Canadian Journal of Psychology, 1969, 23, 459-466. 